\title{
Patterns of Unit Activity in the Rostral Thalamus of Cats Related to Short-Latency Discrimination between Different Auditory Stimuli
}

\author{
C. D. Woody, E. Gruen, O. Melamed, and V. Chizhevsky \\ Mental Retardation Research Center, Brain Research Institute, UCLA Medical Center, Los Angeles, California 90024
}

\begin{abstract}
Short-latency auditory-responsive units were found in the rostral thalamus of cats during performance of conditioned eyeblink responses (CRs) elicited discriminatively by a forward-paired, 70-dB-click conditioned stimulus (CS) as opposed to a backward-paired, 70-dB-hiss discriminative stimulus (DS). Discharges in response to the CS or DS were found in $57 \%$ of 138 units tested. Forty-one percent of units responding to the CS did so at latencies of $<40 \mathrm{msec}$.

After conditioning a discriminative CR to click CS, an increase in the ratio of CS-evoked activity to baseline activity was found relative to that before conditioning. This increase was attributable, in part, to a decrease in baseline activity and, in part, to an increase in the magnitude of response to the CS. These responses preceded early components of the electromyographically measured motor responses with latencies sufficient to contribute to initiation of the movement. After acquisition of the CR, the proportion of CS responsive units also increased.

We conclude that this area of the thalamus, a region thought to support thalamocortical reverberatory activity, also functions to transmit short-latency auditory signals. Our evidence further suggests that this region may participate in the elicitation of conditioned responses by specific auditory stimuli and in discrimination between auditory stimuli of different significance.
\end{abstract}

It is generally agreed that the ability to discriminate between different auditory signals is supported by neurons of the auditory cortex and surrounding cortical areas, yet some ability to perform auditory discriminations is retained after loss of these regions of the cortex (Thompson and Sindberg, 1960; Neff, 1961). For example, one earlier study (Woody et al., 1976) in cats found changes in patterns of unit activity recorded from the auditory association cortex that were isomorphic with acquisition of a discriminative-blink conditioned response (CR) elicited selectively by a click conditioned stimulus (CS), but not by a hiss discriminative stimulus (DS) of equal intensity to the click. Ablation of caudal cortical auditory areas did not suppress acquisition of the CR to the click CS, and such animals could be taught a blink CR (Woody and Yarowsky, 1972) by pairing electrical microstimulation of the motor cortex as a CS with the usual unconditioned stimulus (US). [Cats were unable to learn

Received May 14, 1990; revised July 26, 1990; accepted Aug. 30, 1990.

This research was supported by USPHS NS 25510 . We thank Drs. H. Asanuma, D. Birt, R. Fisher, and E. G. Jones for their advice on various aspects of the studies.

Correspondence should be addressed to Dr. C. D. Woody, UCLA Mcdical Center, Room 58-232, NPI, 760 Westwood Plaza, Los Angeles, CA 90024.

Copyright $\odot 1991$ Society for Neuroscience 0270-6474/91/010048-11\$03.00/0 short-latency blink CRs if the motor cortex was surgically removed (Woody et al., 1974).]

A subcortical auditory pathway to the motor cortex that bypassed the primary and association auditory cortex could explain these findings. Others have proposed that a mixed sensory projection system might exist in the thalamus apart from the posterior (medial geniculate and pulvinar) auditory relay nuclei (e.g., Albe-Fessard and Rougeul, 1958; cf. Goldstein et al., 1960; Evans and Whitfield, 1966), but it has proved difficult to find evidence for a short-latency auditory transmission pathway that could serve this purpose. Studies in rabbits (Gabriel et al., 1980, 1982) indicated that the anteroventral (AV) thalamus might be needed for auditory discrimination, but failed to disclose auditory discriminations performed by thalamic units at latencies $<100 \mathrm{msec}$ after stimulus delivery. In rats (LeDoux et al., 1990), the posterior thalamus was implicated in processing auditory stimuli of acquired emotional significance, but the projections of the involved cells were to the amygdala.

The present investigation examined the auditory function of neurons of the rostral thalamus by evaluating patterns of activity elicited by a click CS, in conscious cats, before and after discriminative conditioning of short- and long-latency eyeblink responses. In addition, excitability and other electrical properties of the neurons, including resting potential and input resistance, were examined by intracellular recordings in the animals.

\section{Materials and Methods}

Studies were performed in 5 cats weighing between 2.5 and $3.0 \mathrm{~kg}$. Intracellular (IC) and extracellular (EC) recordings were obtained from single units of the rostral thalamus while the animals received presentations of click and hiss auditory stimuli (see further details below) Additional IC recordings were made to evaluate characteristic neuronal membrane properties in the conscious animals. The cats were prepared for recording as described previously in detail (Woody and Black-Cleworth, 1973; Woody et al., 1984). Stainless-steel screws were implanted into the skulls of the animals using Na pentobarbital anesthesia $(35 \mathrm{mg} /$ $\mathrm{kg}$, i.p.). The screws were used to fix the head to a stabilizing frame during later, awake training/recording sessions. Penicillin $\mathrm{G}(150,000$ $\mathrm{U}$, i.m.) and benzathine penicillin $\mathrm{G}(150,000 \mathrm{U}, \mathrm{i} . \mathrm{m}$.) were given on the day of surgery, $3 \mathrm{~d}$ later during the recovery period, and at 1-week intervals thereafter, as needed. The cats were loosely restrained by placing their bodies in cloth sleeves during awake recording sessions. Their behavior was continuously observed to evaluate the comfort of the animals, and the studies were discontinued if the animals gave any signs of discomfort such as vocalization and hyperactivity.

Bipolar recordings of EMG activity were obtained bilaterally from the orbicularis oculi (eye) and levator oris (nose) muscles with 4 pairs of Grass E2 subdermal electrodes. The electrodes were led to differential amplifiers (Electronics for Life Sciences, ELSDA - 1), and the data were recorded on a Vetter FM tape recorder (Model D) at DC to $5000 \mathrm{~Hz}$ ( $<1 \%$ falloff). Unless otherwise noted, the EMG activity that was used for analysis of each cat was taken from the left orbicularis oculi muscles. 
EMG activity was analyzed after half-wave rectification and further amplification. A PDP 11-44 computer was used to make on-line, running averages of the periods immediately preceding and following each stimulus presentation. For each experimental trial, 5 sec of EMG data, divided into periods including baseline activity and activity surrounding each stimulus, were collected at 2 -msec intervals. Calibrations in figures designate amplifier gain, which was kept the same while recording EMG responses to the CS and DS. While recordings were being made, averages of every 3 responses $\left(R_{1-3}, R_{2-4}\right.$, etc. $)$ were displayed on a video terminal to permit continuous monitoring of eye blink performance elicited by the CS and DS. The EMG averages were more sensitive detectors of CRs and learning savings than was direct observation of eyelid movement. Thus, EMG averages were used when correlating unit activity with cffects of conditioning.

EC and IC unit activity were recorded with a Dagan high-impedance amplifier and stored on FM tape at the same DC to 5000- $\mathrm{Hz}$ bandwidth as the EMG data above. Analyses of EC activity were confined to spikes of $<20 \mathrm{mV}$ amplitude without an accompanying DC shift. Analyses of IC activity were confined to spikes with accompanying DC shifts, the latter averaging $-54 \mathrm{mV}$ after penetration, (cf. Table 2 resting potentials; Woody and Black-Cleworth, 1973). The satisfactory condition of the studied cells was indicated by the ability to obtain recordings of activity with low, stable rates of baseline discharge and by the equivalence between measurements calculated from the total population of IC recordings and those from cells with resting potentials $\geq 55 \mathrm{mV}$ and action potentials $\geq 60 \mathrm{mV}$ (see Woody et al., 1984 and Results, below). As in earlier studies (Woody et al., 1970; Woody and Black-Cleworth, 1973), no significant differences were found between patterns of spike activity recorded intracellularly and those recorded extracellularly. Consequently, EC and IC data were combined when analyzing patterns of unit activity.

Electrodes were pulled from $1.5-2.0 \mathrm{~mm}$ (outside diameter) theta tubing. When filled with $2.5 \%$ phaseolus leuceagglutinin (PHA-L; Phaseolus lectin; Vector labs) in $3 \mathrm{M} \mathrm{KCl}$ (buffered with sodium phosphate to $\mathrm{pH}$ 7.4) and connected on both sides with $\mathrm{Ag} / \mathrm{AgCl}$ wire, the resistances of the electrodes used for IC recordings ranged from 50 to 15 $\mathrm{M} \Omega$ (and lower for electrodes filled with $\mathrm{KCl}$ alone used for $\mathrm{EC}$ recordings). Capacitance compensation of each electrode was adjusted after insertion into the cortex. For IC units, the level of neuronal excitability was determined as the threshold level of depolarizing current $(40-\mathrm{msec}$ rectangular pulses) required to elicit spike activity. The value of current that repeatedly elicited spike activity at a relatively fixed latency during $50 \%$ or more of pulse applications was taken as the threshold current (Woody and Black-Cleworth, 1973). The apparent input resistance $\left(R_{n}\right)$ was measured from the voltage (current $\times$ resistance; IR) drops produced in the last $5 \mathrm{msec}$ of IC application of \pm 1.0 -nA current pulses, also of 40 -msec duration. The $t_{c}$ of $<0.5 \mathrm{msec}$ of the electrodes allowed nulling of the electrode resistance component by the bridge balance method (Purves, 1981) while making these measurements.

Patterns of unit activity were evaluated using averages of activity made within and across animals (see Figs. 1, 5). The averages were obtained from pooled analyses of the activity of single units (e.g., Figs. 2,4 ) in which spike occurrences were detected with a threshold discriminator (Frederick Haer). Peristimulus time histograms of spike occurrences were made with reference to times of CS and DS onset (uncorrected for $1-\mathrm{msec}$ air conduction delay between sound source and ears of animal) for each cell that was studied. Then, the data from the single units, each cell weighted equally, were averaged. The purpose of the averages made across animals was to obtain initial characterizations of representative patterns of unit activity that could be related (or not) to discriminative elicitation of the conditioned behavioral response.

Auditory receptivity of units was defined in 2 ways: (1) "inclusive" on the basis of increased activity (above the peak of baseline activity in each 4-msec bin of the 240-msec periods of discharge preceding the CS and DS) at any time in the 160 -msec period following CS or DS presentation, and (2) "selective" on the basis of more substantially increased activity ( $\geq 2$ discharges above the peak, per $4 \mathrm{msec}$, of both 40-msec periods of preceding baseline activity) also at any time during the 160-msec period following CS or DS presentation. [Each criterion was devised so that the latency of any response to the CS (or DS) would be unbiased within the 160 -msec period after stimulation.] The selective criterion was used for estimating percentages of auditory-responsive units because it posed a more rigorous test of responsiveness. The inclusive criterion was used to ensure that weakly responsive cells in a distributed processing system would be sampled and included in assessment of patterns of response.
Electrodes were introduced into the rostral thalamus using a previously implanted stereotaxic guide tube. The depth at which each unit was recorded was noted. Locations of recordings were determined using the approach of Steriade and Glenn (1982), that is, from serial sections of tissue with reconstructions of electrode tracts plus associated microdrive coordinates, or, alternatively, by EC (and, in a few instances, IC) pressure injections of PHA-L (sometimes mixed with 4\% HRP) made at the conclusion of recordings. [Our methodologies for pressure injection have been described earlier (Sakai et al., 1978).] An example of a PHA-L injected, auditory-responsive cell is shown later in Figure $8 C$. (More detailed analyses of intracellularly and extracellularly marked neurons from these and other, more posterior thalamic regions are being prepared for a separate report.) The procedure of Porter and Sakamoto (1988), based on the method of Gerfen and Sawchenko (1984), was used to react the tissue for PHA-L. The peroxidase-diaminobenzidine treatment used as part of that procedure also detected the original HRP when present. Loci at which markings were found (center for multiple markings) for each animal are shown in Figure 7. Recordings were obtained within 1-2 $\mathrm{mm}$ of these loci in the anterior-posterior or medial-lateral planes and $2-3 \mathrm{~mm}$ vertically, which sufficed to localize the recordings within the rostral thalamic region.

Behavioral training. Conditioned (CS), unconditioned (US), hypothalamic (HS), and discriminative (DS) stimuli were presented in timed sequences during trials of behavioral conditioning (see Kim et al., 1983; Hirano et al., 1987, for any details not given below). The click CS was generated by a rectangular pulse of $1-\mathrm{msec}$ duration (delivered to a loudspeaker placed 1-2 feet in front of the animal). The clicks were of 70-dB intensity (General Radio Company dB meter 1565-A) measured at the ears of the animals. A hiss of comparable intensity to the click (see Kim et al., 1983, for amplified earphone recordings of the stimuli) was employed as the DS. A tap delivered to the glabella served as the US. It was produced by means of a small metal rod driven electromechanically by a solenoid to strike a screw that was previously implanted in the glabella (see Woody et al., 1974, for complete details). The HS consisted of a train of 4 electrical stimuli delivered to the lateral hypothalamic region as described more fully below.

Adaptation consisted of an initial training period during which click and hiss were presented $4.4 \mathrm{sec}$ apart. Conditioning was accomplished thereafter by pairing the click CS with the glabella-tap US and HS at interstimulus intervals (ISIs) of 570 and $10 \mathrm{msec}$, respectively. The hiss DS was presented $3.8 \mathrm{sec}$ after the HS. A $10-\mathrm{sec}$ intertrial interval (ITI) was used to reduce the total time between the beginning of training and establishment of the conditioned blink response. This facilitated electrophysiological studies of unit activity, all of which were made during 10-20 repeated presentations of the CS and DS without US or HS (as during adaptation). These testing trials were followed by repeated conditioning trials to prevent extinction of the CR. Delivery of CS, US, HS, and DS during training and testing was controlled by means of the PDP 11-44 computer. EMG responses to the CS and DS were measured so that unit activity could be compared with production of the CR.

These initial studies did not evaluate the associative consequences of conditioning on unit activity. Earlier studies indicated that development of the conditioned behavior depended on the order of stimulus presentation (Woody et al., 1974; Kim et al., 1983), that the hiss was a satisfactory CS when the order of presentation was reversed (Engel and Woody, 1972; Hirano et al., 1987), and that pseudorandom pairing of CS, DS, and US did not lead to acquisition of the CR (Woody et al., 1976). Behavioral studies were also performed earlier that evaluated other associative consequences of pairing these stimuli (Kim et al., 1983; Hirano et al., 1987). The results indicated that the behavioral CR met the usual tests of associative conditioning.

Hypothalamic stimulation. Electrical stimulation of the hypothalamus was accomplished with bipolar, stainless-steel, concentric electrodes (David Kopf Instruments, NE 100). The diameters of the concentric electrodes were 0.2 and $0.5 \mathrm{~mm}$, respectively, each with an exposed tip length of $0.5 \mathrm{~mm}$. Each train of hypothalamic stimulation (HS) consisted of 4 brief rectangular pulses of $100-200-\mu \mathrm{sec}$ duration, presented at $50 \mathrm{~Hz}$. Currents of $0.6-5 \mathrm{~mA}$ were used with intensities adjusted to obtain optimal behavioral effects. The lateral hypothalamic region was selected as the locus of stimulation on the basis of earlier studies in which HS was used successfully to produce rapidly acquired blink CRs (Kim et al., 1983). Because most of the cats required electrical HS of $>1-\mathrm{mA}$ intensity to learn CRs rapidly, the effects of HS were not likely to have been confined to the local regions. At the end of each experiment (10-14 d after the last injection of PHA-L), a steady current $(1 \mathrm{~mA}, 20 \mathrm{sec})$ was delivered through the HS electrode in order to 

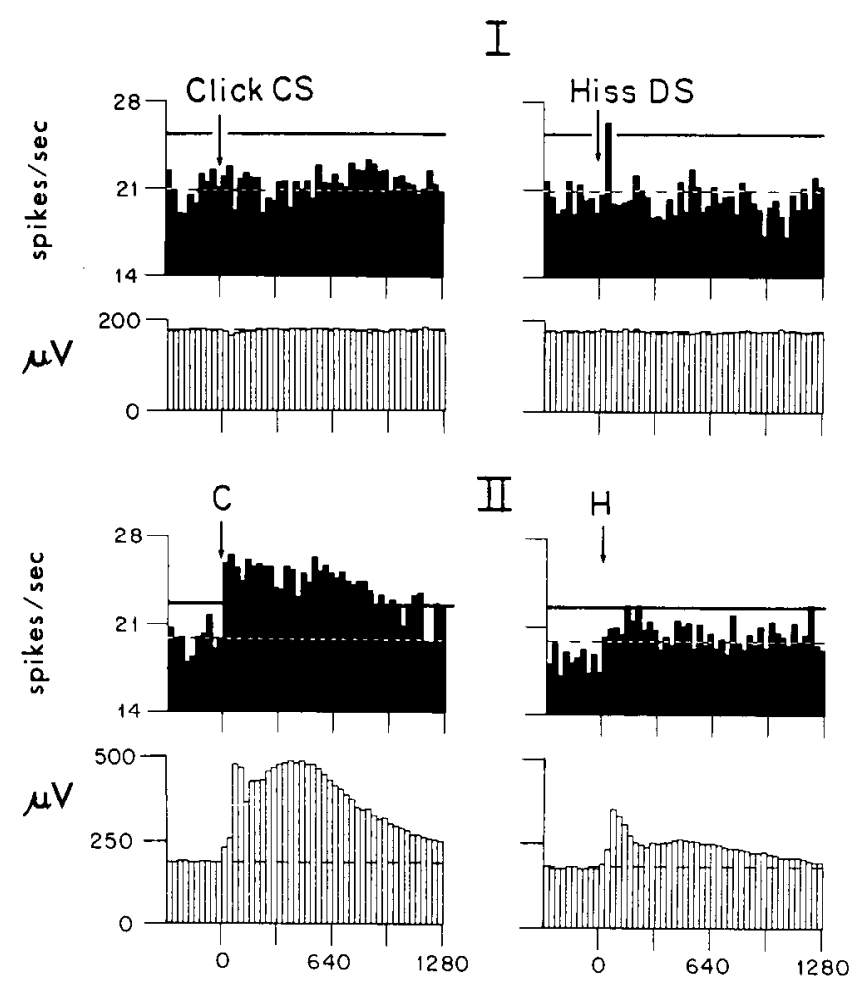

$\mathrm{ms}$

Figure 1. Histogram averages of spike activity (solid bars) and corresponding EMG activity (open bars) during naive ( $I, n=116$ cells) and conditioned ( $I I, n=138$ cells) behavioral states. (Data encompass all cells and all trials from all cats, 1 naive, 2 conditioned, and 2 naive and conditioned.) Responses to click CS $(C)$ and hiss DS $(H)$ are as indicated. The stimuli were delivered at time 0 (vertical arrows). Calibrations for spike activity (spikes/sec) and EMG activity $(\mu \mathrm{V}$ ) are as shown. Time scale is in msec. Baseline levels of spike discharge and EMG activity (dashed lines in this and following figures) are the mean of the activity in the period from 0 to $380 \mathrm{msec}$ preceding delivery of the CS. Solid horizontal lines are $3 Z$ above baseline spike activity.

produce a small lesion. Animals were then killed with sodium pentobarbital and perfused with physiological saline followed by $10 \%$ formalin or $4 \%$ paraformaldehyde to confirm locations of electrodes by histologic analysis. (The locations are shown in Fig. 7.)

\section{Results}

Unit activity to auditory stimuli before and after conditioning Spike activity in response to click CS and hiss DS was recorded from a total of 254 units in 5 animals. Of these, 116 units werc studied before conditioning and 138 after conditioning of a blink CR elicited discriminatively by click CS (Fig. 1). Two of the animals had unit recordings during both naive and conditioned states to permit within-animal analyses of changes in activity.

Patterns of discharge elicited by the CS and DS were first characterized (see Materials and Methods, Fig. 1) using grand averages of the results from all units in all animals. The magnitude of activity in response to the stimuli was evaluated using $Z$ scores (Winer, 1971) relative to the SD of the prestimulus baseline activity.

In the naive animals (Fig. 1, I), the response to the CS was not clearly separated $(\ll 3 Z)$ from the baseline activity. The response to the DS showed a peak in the period 33-64 msec after hiss delivery. After conditioning, the response to the CS was $7 Z$ larger than the baseline activity and $4 Z$ greater than that to the DS, yet only moderately exceeded the peak response to the CS (and did not exceed that to the DS) before conditioning. The baseline activity of the total cell population fell from 20.8 \pm 1.2 spikes/sec (mean \pm SD) before conditioning to $19.8 \pm$ 0.9 spikes/sec after conditioning ( $p<0.0001, t=7.58$, df $=$ 252). The peak response to the CS in the first $100 \mathrm{msec}$ after delivery increased from $24.1 \pm 1.2 \mathrm{spikes} / \mathrm{sec}$ to $26.4 \pm 0.9$ spikes/sec $(p \ll 0.0001, t=17.4, \mathrm{df}=252)$. The variance of the baseline activity was smaller in the conditioned than in the naive state: 0.9 versus 2.0 spikes/sec, respectively. A similar reduction of variance after conditioning was found in analyses made within individual animals (see Fig. 5). Within-animal analyses of cells responsive to the CS found even more pronounced decreases in mean baseline activity after conditioning: $20 \pm 4.7$ to $16 \pm 1.5$ spikes/sec and $23 \pm 4.8$ to $11.5 \pm 1.4$ spikes/sec $(p<0.001 ; t=5.35$ and 8.41 for repeated measures within each of the 2 animals; $\mathrm{df}=66$ and 37, respectively).

Averages of EMG activity of the orbicularis oculi muscles recorded at the same time as unit activity showed no consistent responses before conditioning, but after conditioning, a discriminative blink CR was elicited by the CS, with a greater response to the CS than DS (Fig. 1).

Figure 2 shows examples of IC and EC recordings of activity from thalamic units. The EC unit (Fig. $2 i-i i i)$, recorded from a conditioned animal, had a sustained ( $\gg 250 \mathrm{msec}$ ) increase in discharge in response to the $\mathrm{CS}$ above the level of background activity. The peak of the response to the CS occurred between 33 and $64 \mathrm{msec}$ after CS delivery and was greater than that to the DS. The IC unit (Fig. 2iv) from the same conditioned animal had a low rate of baseline activity and a brief increase in discharge in the period 50-100 msec after delivery of the CS. The input resistance of this cell was calculated to be $11 \mathrm{M} \Omega$.

\section{Pattern of activity in CS-responsive units}

The temporal patterns of response to the CS after conditioning were assessed in more detail in units with an increased discharge in the $160 \mathrm{msec}$ following presentation of the CS (Fig. 3). Two different criteria (inclusive or selective; see Materials and Methods) were used to define the auditory-responsive units. The inclusive criterion was used when it was important that small responses to the CS be detected and incorporated into the analyses (e.g., Figs. $2 i v, 4 i$ ). The selective criterion was used when evaluating activity (and percentages) of units showing more distinct auditory responses (e.g., Figs. $2 i-i i i, 4 i i)$.

Onset and timing of activity in relation to delivery of CS. Averages of the activity of CS- and DS-responsive cells in the naive animals had small, early elevations in firing $2-3 Z$ above baseline that extended beyond the initial $160 \mathrm{msec}$ after stimulus presentation, using either selective or inclusive criteria. Figure $3 A$ shows results using the inclusive criterion. In the conditioned animals, the peaks were $9-11 Z$ above baseline with a decline 700-1000 msec after stimulus delivery (Fig. 3B,C).

After conditioning, the poststimulus histogram averages of activity disclosed increases in rates of discharge above the prestimulus, baseline activity as early as 6-8 msec after CS delivery (Fig. $3 D$, right, diagonal arrow). Increases in unit activity above baseline were found to precede the onset of even the shortest latency component of the CR (see Kim et al., 1983; Hirano et al., 1987 for further studies and description of different components of the CR itself) and were sustained during (and beyond) initiation of larger, later components of the CR.

Activity supporting discrimination of $C S$ from $D S$. The magnitude of response of CS-responsive cells to click CS was com- 
i.
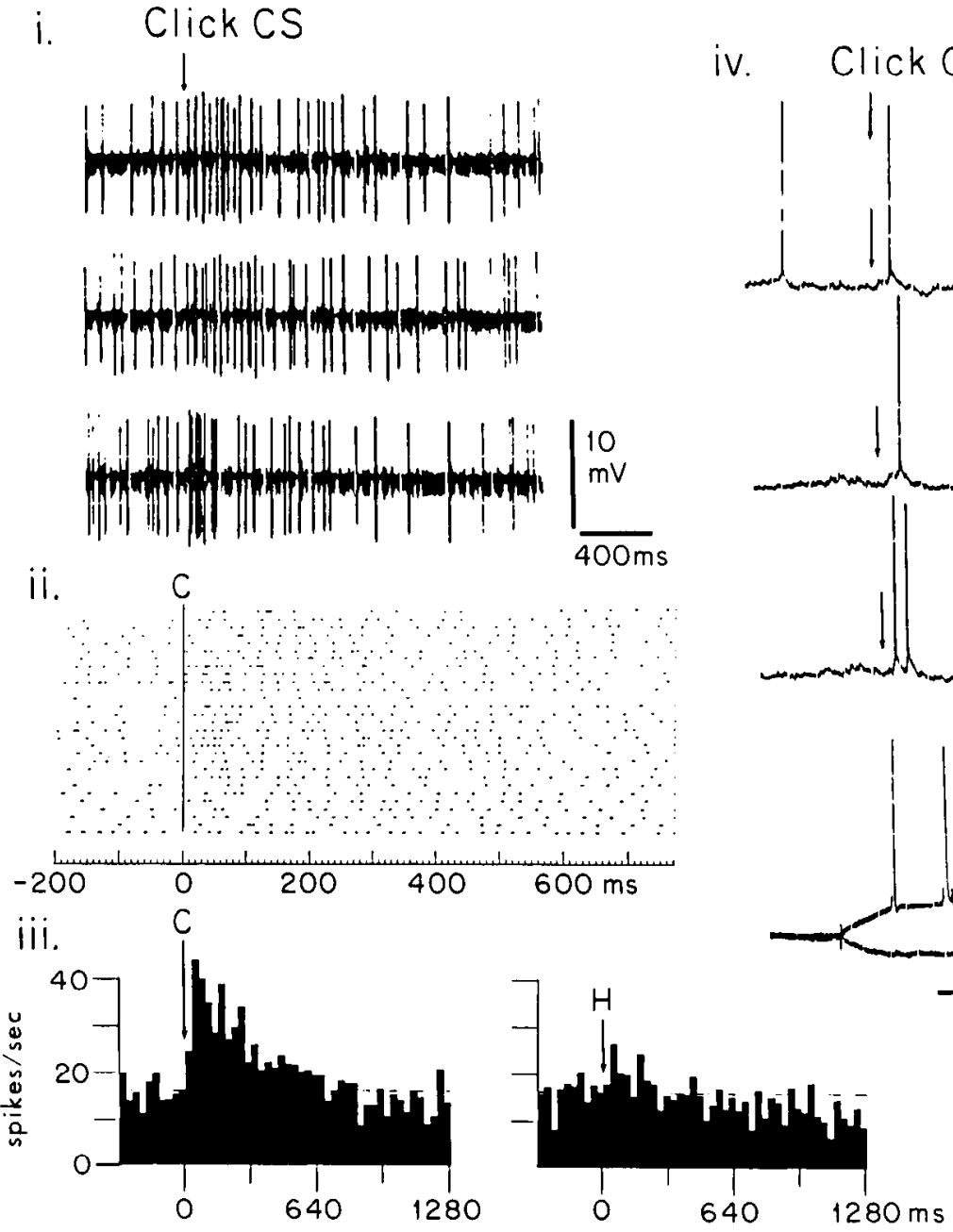

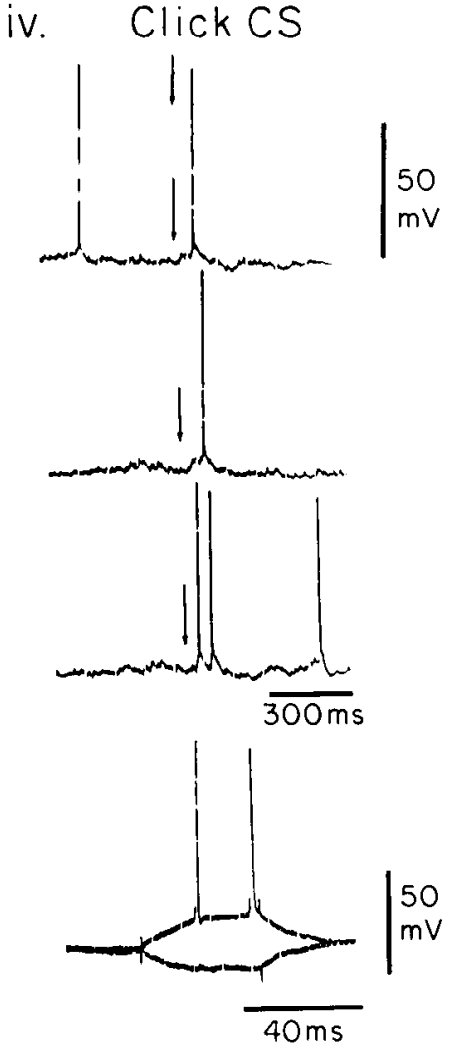

V
Figure 2. Examples of recordings from single units in animals conditioned to blink in response to click CS. $i$, Responses of an extracellularly recorded unit to 3 presentations of the CS. $i i$, Raster of the responses of unit in $i$ to serial presentations of the CS (C). iii, Averages of the responses in $i i$ to the CS $(C)$ and to concurrent (with 3-sec delay; see Materials and Methods) presentations of the hiss DS (H). iv, Responses of an intraccllularly recorded unit to 3 successive presentations of the CS. Time of click delivery shown by arrows. Below is response of the unit to intracellularly applied $\pm 1 \mathrm{nA}$ rectangular currents. pared with that of DS-responsive cells to hiss DS (Fig. $3 A-C$ ) to evaluate whether this activity might contribute to the ability to discriminate between the CS and DS.

Initially (Fig. $3 A$ ), the response to the CS was no greater than that to the DS, an auditory stimulus of similar intensity (see Materials and Methods). After conditioning, the response to the CS was larger than that to the DS in cells defined by selective but not by inclusive criterion (Fig. $3 B, C$ ), indicating that this increase occurred mainly in cells with large responses to the CS.

\section{Activity before and after conditioning within single animals}

Patterns of activity of CS-responsive units (inclusive criteria) were compared in different animals to determine if the changes that occurred after conditioning were similar from animal to animal (and to evaluate the possibility that activity from only one animal disproportionately influenced the averaged results). Figure 5 shows averages of activity recorded from 2 different animals. Each animal showed changes in activity after conditioning characterized by (1) a decrease in spontaneous firing and (2) an increase in signal-to-noise $(\mathrm{S}: \mathrm{N})$ ratio of the response to click CS.

\section{Proportion of CS-responsive units before and after conditioning}

After dividing units into those responsive to click $(\mathrm{C})$, hiss $(\mathrm{H})$, both click and hiss (B; same selective and inclusive criteria for response as earlier), and the remaining unresponsive (or less responsive) cells ( 0$)$, the proportions of units before and after conditioning were examincd (Tablc 1). Before conditioning, 43\% of units showed responses to click or hiss defined by selective criterion. After conditioning, 57\% of units showed such responses, and $80 \%$ of these auditory-responsive units had increases in activity in the first $100 \mathrm{msec}$ after stimulus presentation (Table 2). Forty-one percent of units responding to the $\mathrm{CS}$ after conditioning did so at latencies of $<40 \mathrm{msec}$.

After conditioning, an increase in the proportion of auditoryresponsive units was found in the CS-responsive $(C+B)$ units, defined by either inclusive or selective criteria (Table $1 ; p<$ $0.02, \chi^{2}$ test). This increase was correlated with the ability of the animal to discriminate between CS and DS in performing the CR. [There was no increase in the proportion of units that responded to the DS; instead, a decrease was observed (Table 1, $\mathrm{H}$ cells).]

\section{Comparison of activity recorded at different thalamic regions}

Figure 6 shows the activity of CS-responsive units (inclusive criteria, $\mathrm{C}+\mathrm{B}$ cells) recorded from different areas within the same animal after establishment of a blink CR. Comparison of unit activity recorded from the rostral thalamus with that recorded 3-4 mm more posteriorly (from pulvinar) or 3-4 $\mathrm{mm}$ more anteriorly (from caudate) indicates that the patterns of activity differed between regions. Early ( $8-10 \mathrm{msec})$, long-la- 
A
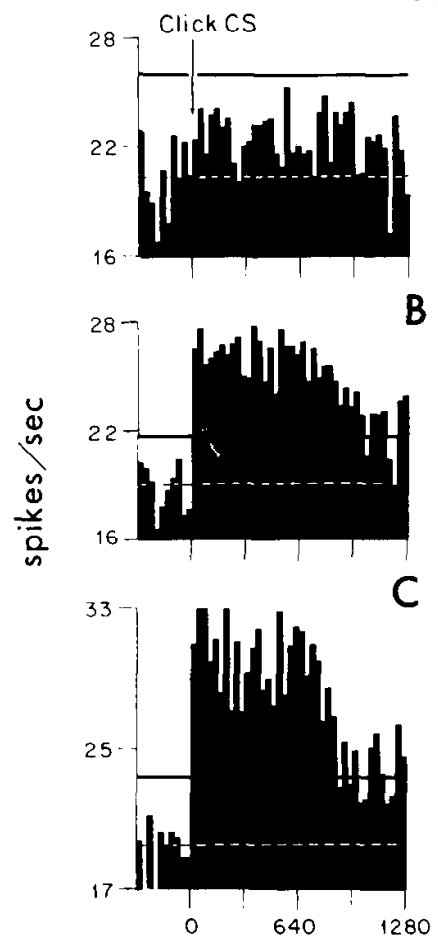

B

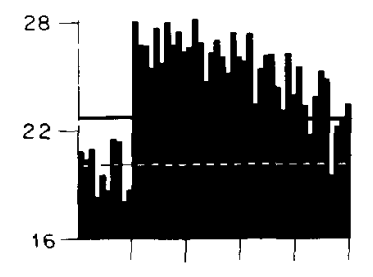

C

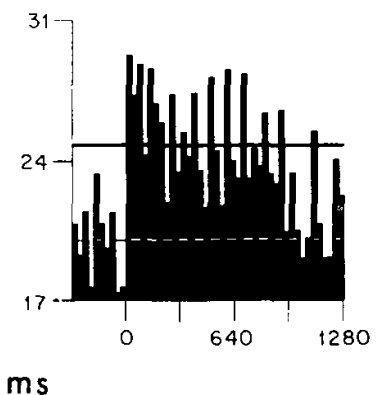

D
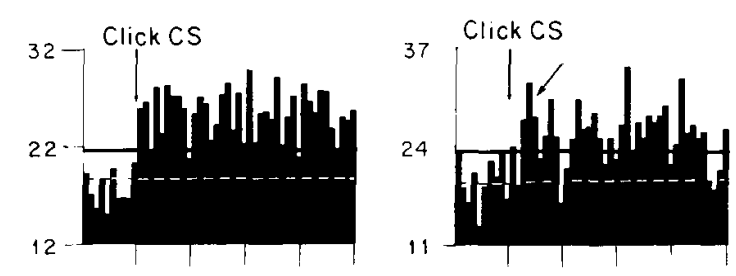

$\mathbf{E}$
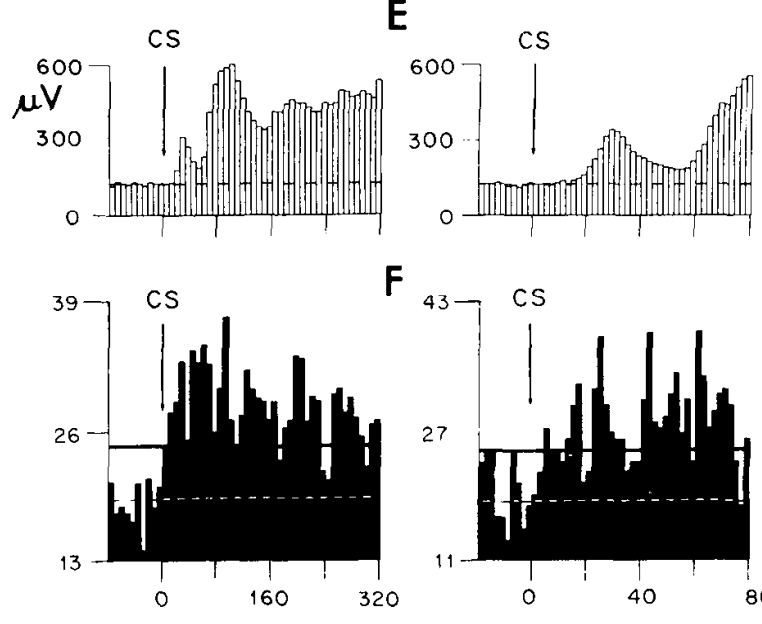

$\mathbf{F}$

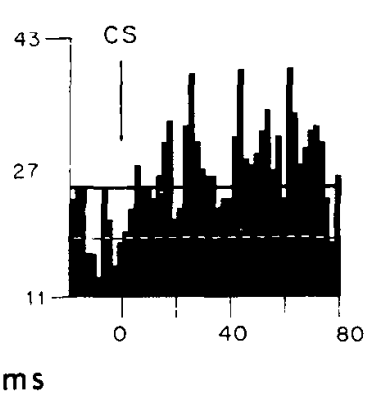

Figure 3. $A-C$ show histogram averages of activity of units (solid bars) responsive to click CS (left) and hiss DS (right). Data from naive $(A)$ and conditioned $(B, C)$ behavioral states are compared. $A$ and $B$ use inclusive criterion for defining a responsive unit; $C$ uses selective criterion (see Materials and Methods). $D$ and $F$ show averages at different time scales of inclusive $(D)$ and selective $(F)$ postconditioning spike data for comparison with EMG activity ( $E$, hollow bars), recorded concurrently (with data in $D$ ) from orbicularis oculi muscles engaged in producing blink CRs. Time calibrations in lower histograms apply to those above as well. Time scales in $D-F$ were selected to show early latency components of the CR.

Figure 4. $i$-iii show raster displays of activity recorded from single units. $i$ and $i i$. The response to click $(C)$ of 2 different units recorded in naive animals before any conditioning. $i i i$, The response of a unit from a conditioned animal to the hiss DS $(H)$. (Because the low background firing rates made it difficult to detect units with reduced discharges to the stimuli, separate analyses of those units were not made in the present studies.) Time calibrations are in msec. $i v-v i$ show LTS discharges characterized by a depolarizing-hyperpolarizing wave producing spiking with a postspike peak (arrows): $i v$ and $v i$ have long-lasting hyperpolarization after l-nA depolarizing current pulses; $v$ and $v i$ have additional, artificially injected, steady hyperpolarization of $1.5 \mathrm{nA}$. $i$ $v i$ are from the same unit. Time and amplitude calibrations are as indicated.
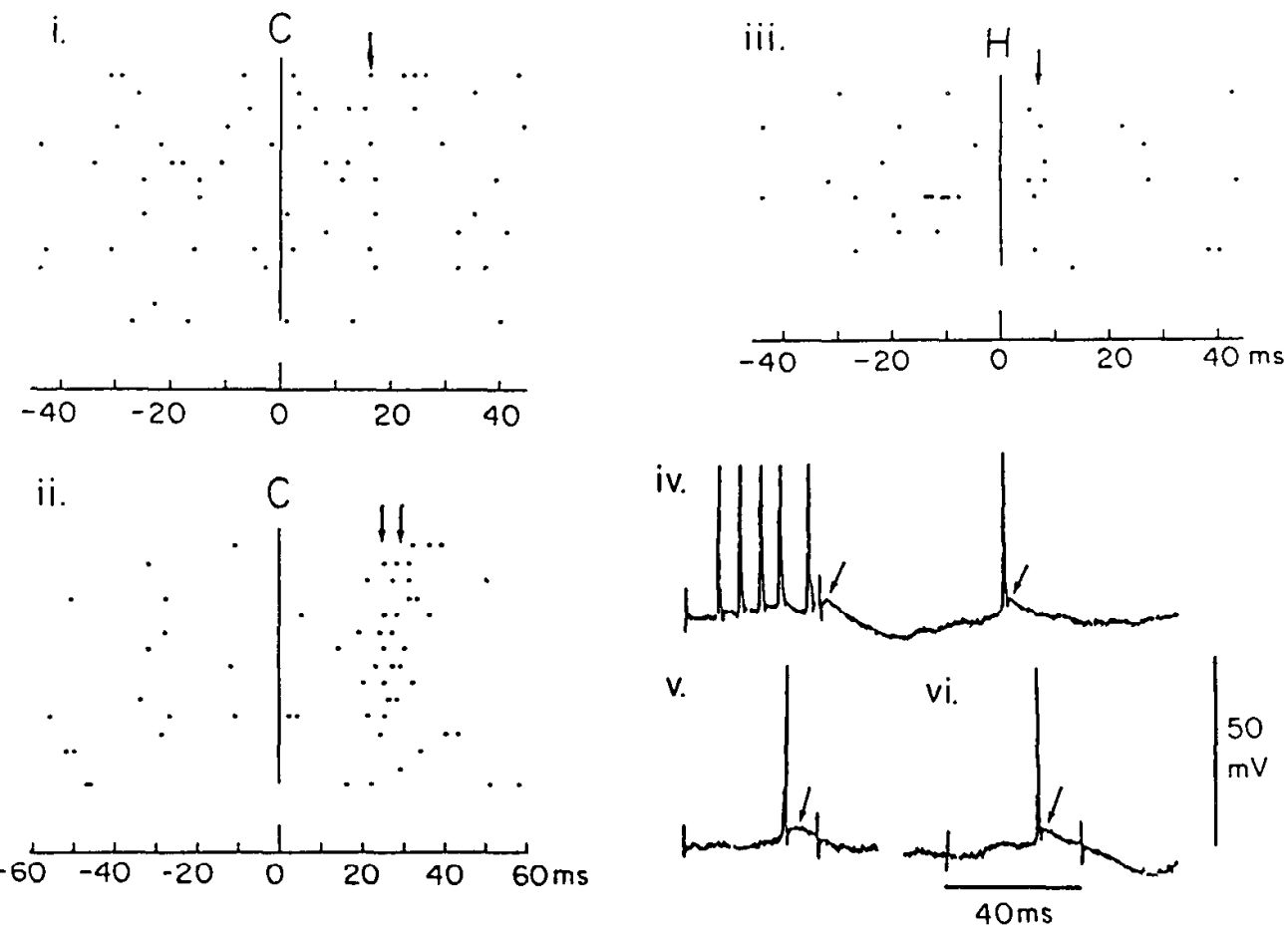
tency $(128-160 \mathrm{msec})$, and late ( $>600 \mathrm{msec})$ increases in activity in response to the CS (or DS) were found in recordings from the rostral thalamus. In the pulvinar, a response was observed at 14-16 msec and was sustained over a period of $\geq 64 \mathrm{msec}$ after delivery of the CS. (The early responses are shown in more detail with expanded time scales in the lower half of Fig. 6.) In the caudate, activity increased in the period $64-400 \mathrm{msec}$ after the CS, as well as in later periods (>600 msec after the CS). The response of units of the rostral thalamus (and caudate) outlasted that of the units recorded more posteriorly from the pulvinar.

\section{Electrical properties of intracellularly recorded units}

Resting potentials (RPs) measured directly in vivo from 103 intracellularly recorded units averaged $-54 \mathrm{mV}$ (Table 3). Input resistances measured in 32 cells with $\mathrm{RP} \geq 55 \mathrm{mV}$ and $\mathrm{AP} \geq$ $60 \mathrm{mV}$ averaged $10.5 \mathrm{M} \Omega$. Three percent of the units had detectable low-threshold spike (LTS) discharges to $\pm 1 \mathrm{nA}$ current (Fig. $4 i v-v i)$. Long-lasting ( $>100 \mathrm{msec}$ ) hyperpolarization after 1 -nA depolarizing pulses was observed in $6 \%$ of the cells (cf. Roy et al., 1984).

Input resistance, RP, and excitability to depolarizing current pulses (see Materials and Methods) were compared before and after conditioning (Tables 3,4). Mean RP increased slightly (but not significantly) after conditioning in accompaniment with the decrease in spontaneous activity. No changes were found in mean excitability or input resistance over the total population of cells, but when cells were separated according to their response to CS or DS, the excitability to intracellularly injected current of CS-unresponsive cells (including those cells responding to the DS alone) was lower after conditioning (Table 4, $\mathrm{H}+0$ : mean $0.6 \pm 0.3 \mathrm{nA}$ (before) vs. $0.9 \pm 0.5 \mathrm{nA}$ (after conditioning), $t=2.14, \mathrm{df}=43, p<0.05)$.

\section{Anatomical loci of recording and hypothalamic stimulation}

Figures 7 and 8 show anatomical locations of thalamic recordings and HS. In Figure 7, the cat with recordings at $10.5 \mathrm{~mm}$ (more lateral star) was the animal shown in Figure 5 (left); that with recordings at $9.5 \mathrm{~mm}$ was the animal in Figures 5 (right) and 6 . The recording locations within the rostral thalamus ranged from the nucleus reticularis to the border of the lateralis dorsalis nucleus, with many cells recorded in or near the dorsal thalamic peduncle (see Fig. 8). Short-latency ( $<40 \mathrm{msec}$ ) auditory-responsive cells were found throughout these regions (i.e., in each animal), suggesting that they were not confined to a single nucleus (i.e., reticularis, nucleus ventralis anterior, nucleus lateralis dorsalis, or nucleus anterior ventralis). [Because we did not

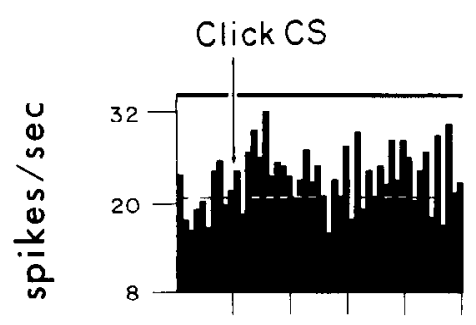

I
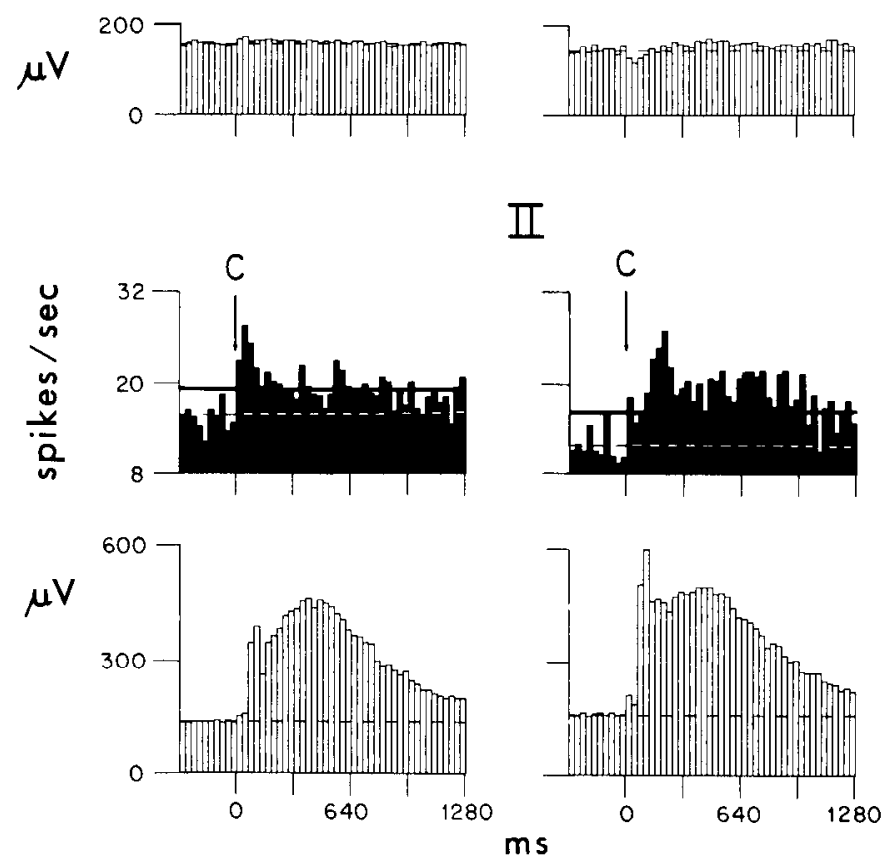

Figure 5. Histogram averages from 2 separate cats (left, right) of spike activity (solid bars) and EMG activity (open bars) in response to click CS (C) before ( $I, n=19$ and 26 cells for left and right, respectively) and after ( $I I, n=49$ and 13 cells, respectively) conditioning. An improvement in the S:N ratio of activity in response to the CS occurred in each animal after conditioning. Data are from all cells in each cat that responded to the CS with an increased discharge in the initial 160 msec after stimulus delivery ( $\mathrm{C}+\mathrm{B}$ cells, inclusive criteria). Calibrations for spike and EMG activity are the same for each animal; other calibrations and labeling are as in Figure 1.

know in advance where in the thalamus, apart from the medial geniculate nucleus, short-latency unit responses supporting auditory discrimination might be found, separate studies (Melamed and Woody, 1989) surveyed middle (lateralis dorsalis and centrolateral) and posterior (pulvinar and lateralis posterior)

Table 1. Percentage and number ( $N$ ) of CS- and DS-responsive cells as a function of behavioral state

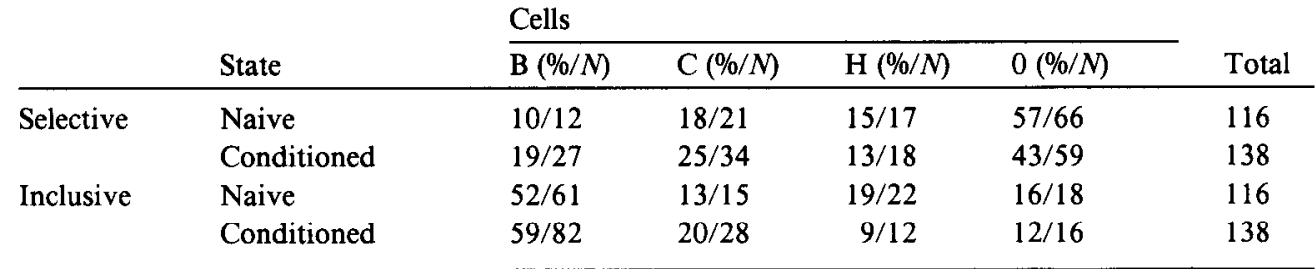

Selective: response defined by activity $\geq 2$ discharges above peak of baseline in any 4-msec period from 0 to $160 \mathrm{msec}$ after click and hiss, respectively. Inclusive: response defined by activity $>$ peak of baseline in any 4-msec period from 0 to $160 \mathrm{msec}$ after click and hiss, respectively. Cells: B, responsive to both click and hiss; C, responsive to click only; $\mathrm{H}$, responsive to hiss only; $0=$ unresponsive to click or hiss. State: defined as in text. Numbers of CS-responsive (B $+\mathrm{C})$ cells increase after conditioning $\left(p<0.02, x^{7}\right.$ test) using either selective or inclusive critcria to define a responsive cell. 
Ant. Thalamus
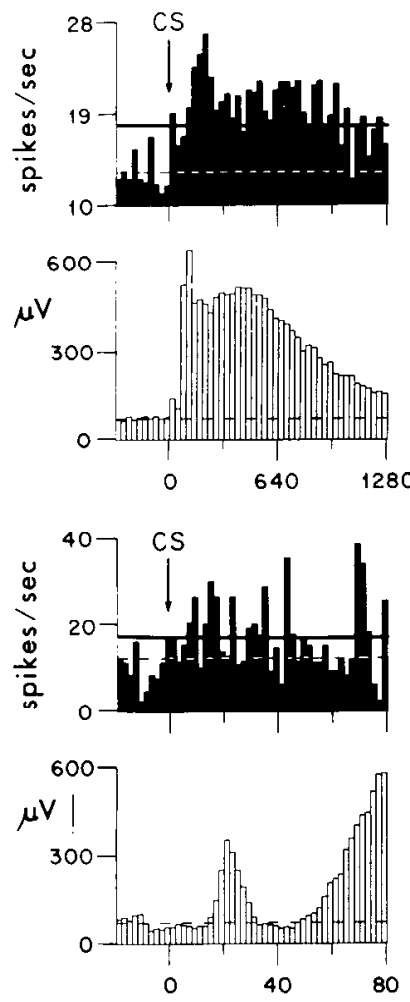

Post. Thalamus
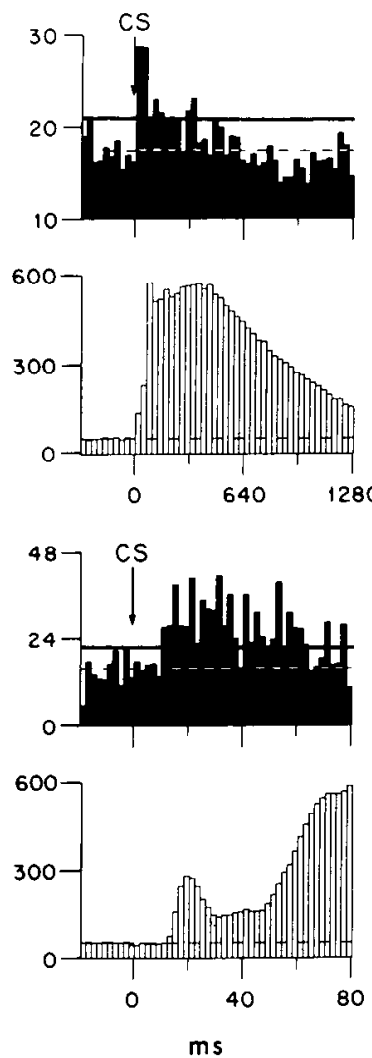

Caudate
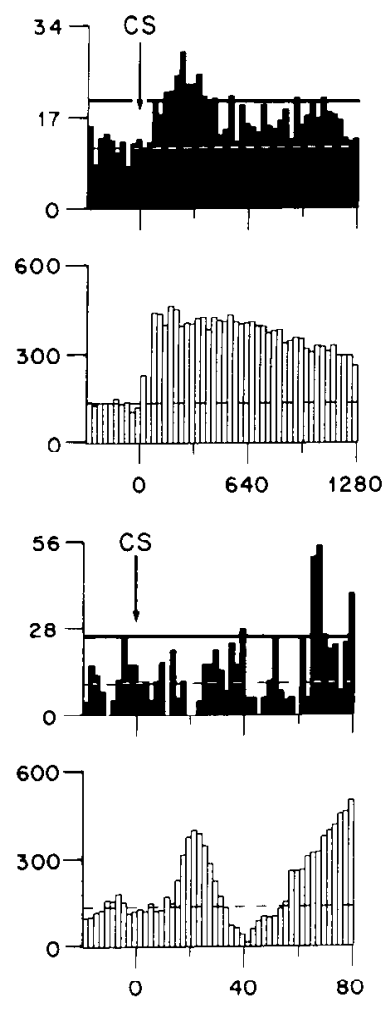

$n=28$ cells) areas. Data from $C+B$ cells, inclusive criteria. Calibrations and other labeling are as in Figure 1.

Figure 6. Histogram averages of postin response to click CS obtained from 3 different recording areas in a single animal. Separate histograms of EMG activity (open bars) show the associated conditioned response. Different patterns of unit response to the CS were found at the rostral thalamic (left, $n=$ 13 cells), posterior thalamic (middle, $n$ $=37$ cells), and anterior caudate (right, the recorded units were found to respond to auditory stimuli with an increased discharge. Eighty percent of the auditoryresponsive cells in the conditioned animals responded at latencies of $<100 \mathrm{msec}$ to these stimuli, with $41 \%$ responding at latencies $<40 \mathrm{msec}$ (Table 2). Analysis of poststimulus histogram averages (Fig. $3 D$ ) disclosed the earliest onsets of response to be as short as those of neurons of the primary auditory cortex (AI and AII), thus admitting the possibility that neurons of this region might serve a primary auditory pathway as well as a mixed ascending pathway proposed by earlier investigators. The latter has been described as nonspecific, but may better be termed mixed in view of (1) the multiple types of sensory information transmitted (Thompson et al., 1963), (2) the mixed latencies of response to the brief click CS, and (3) the observation of specific patterns of activity elicited by stimuli of specific, discriminative significance to the organism.

Changes in unit responses after conditioning (Fig. 1) consisted primarily of a decrease in baseline activity and an increase in the $S: N$ ratio of $C S$ elicited activity. Each animal compared before and after conditioning showed these changes (Fig. 5). sion is served by neurons of the rostral thalamus. Over half of

Table 2. Number of cells by latencies of onset of response to click (msec after CS delivery)

\begin{tabular}{lllllllllll} 
& $0-8$ & $9-16$ & $17-24$ & $25-32$ & $33-40$ & $41-48$ & $49-56$ & $57-64$ & $65-72$ & $73-80$ \\
\hline Naive & 5 & 0 & 2 & 3 & 5 & 2 & 2 & 1 & 2 & 4 \\
Conditioned & 5 & 4 & 6 & 7 & 3 & 4 & 3 & 3 & 2 & 3 \\
\hline
\end{tabular}


Table 3. Resistance, resting potential, and excitability before ADP and after conditioning

\begin{tabular}{|c|c|c|c|c|c|c|}
\hline & \multicolumn{2}{|c|}{$\underline{\text { Resistance }(\mathrm{M} \Omega)^{a}}$} & \multicolumn{2}{|c|}{$\begin{array}{l}\text { Resting potential } \\
(\mathrm{mV})\end{array}$} & \multicolumn{2}{|c|}{ Excitability (nA) } \\
\hline & ADP & $\begin{array}{l}\text { Condi- } \\
\text { tioned }\end{array}$ & ADP & $\begin{array}{l}\text { Condi- } \\
\text { tioned }\end{array}$ & ADP & $\begin{array}{l}\text { Condi- } \\
\text { tioned }\end{array}$ \\
\hline Mean & 10.3 & 10.5 & 52.7 & 54.1 & 0.67 & 0.79 \\
\hline$n$ & 8 & 24 & 31 & 72 & 34 & 74 \\
\hline SD & 2.2 & 2.3 & 7.6 & 7.7 & 0.40 & 0.38 \\
\hline
\end{tabular}

${ }^{a}$ Measured in cells with resting potential $\geq 55 \mathrm{mV}$ and action potential $\geq 60 \mathrm{mV}$. ${ }^{b}$ Includes 5 additional cells in which excitability but not resting potential could be measured due to electrode polarization.

Also, patterns of discharge recorded from the rostral thalamus differed from those recorded from other nearby areas within the samc animals (Fig. 6).

The way in which sensory information was processed by cells of the rostral thalamus was different, with 1 exception, from that of cells of the auditory association cortex and motor cortex. The latter showed no change in spontaneous firing rate after development of a discriminative-blink CR to similar auditory stimuli; the former showed an increase in spontaneous firing (Woody et al., 1970, 1976). [The exception was that, after conditioning, the increase in numbers of neurons with responses beginning 9-16 msec after CS delivery closely mirrored that found earlier in the motor cortex (see Woody et al., 1970, their Fig. 5A).] Processing in the rostral thalamus also differed from that in the midthalamus and posterior thalamus. The midthalamus showed no decrease in spontaneous firing after conditioning (Melamed and Woody, 1989); the posterior thalamus showed a different pattern of response (Fig. 6).

The earliest responses of rostral thalamic units preceded initiation of the CR. Latencies of unit response of 9-16 msec would be early enough to support auditory transmission through the motor cortex or directly to the facial nucleus, where activation occurs $17 \mathrm{msec}$ after delivery of the click CS (Woody and Brozek, 1969). [In the auditory association cortex (Woody et al., 1976), the main increase in discharge after conditioning occurred 12$16 \mathrm{msec}$ after CS delivery.] The later increases in activity of rostral thalamic units were sustained beyond the peak of the motor response, indicating that some late activity might represent somatosensory feedback from the movement itself.

\section{Support of auditory discrimination}

Taken together, the findings in Figure 1 and Tables $1-4$ suggest that neurons of the rostral thalamic region process auditory information with a high level of sensitivity to every stimulus until the context changes to one in which certain stimuli must be discriminated from others. There then occurs (1) an increase in the $\mathrm{S}: \mathrm{N}$ ratio consequential, in part, to a reduction in baseline

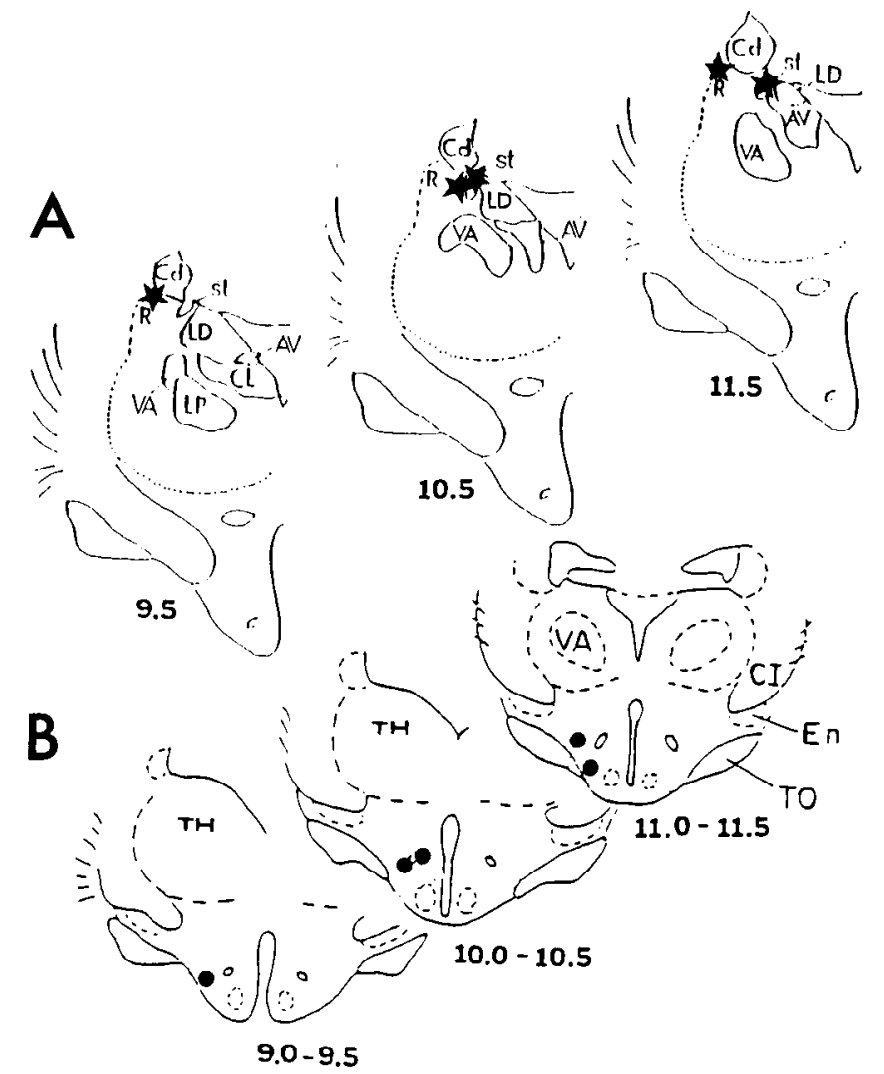

Figure 7. A, Locations of the rostral thalamus from which recordings were made. $B$, Locations of hypothalamic stimulating electrodes. $R$, nucleus reticularis; $V A$, ventralis anterior; $L D$, lateralis dorsalis; $L P$, lateralis posterior; $C L$, centralis lateralis; $A V$, anterior ventral; $C d$, caudate; st, stria terminalis; $C I$, internal capsule; $T H$, thalamus; $T O$, optic tract; $E n$, entopeduncular nucleus. [Tissue was cut in the parasagittal plane. Summaries of (reconstructed) data werc drawn in the morc familiar horizontal plane.] Numbers are anterior stereotaxic planes in millimeters from the interaural line of the Snider and Niemer atlas (Snider and Niemer, 1961).

discharge, (2) an increase in the number of units responsive to the stimulus that must be discriminated (i.e., the CS), (3) an enhancement of large responses to the CS relative to those to the DS (Fig. 3C), and (4) a decrease in excitability to intracellularly injected current in CS-unresponsive cells, including those responsive to the DS alone (Table 4). Each of these changes would facilitate discrimination of stimuli of significance, such as CS, from other stimuli. The transmission of the CS would be enhanced by the increase in the $S: N$ ratio and by the increased numbers of cells recruited to respond (Table 1).

\section{In vivo electrical properties}

The electrical properties of neurons in the conscious preparation had many similarities with those of thalamic neurons measured

Table 2. Continued

\begin{tabular}{lllllllll}
$81-88$ & $89-96$ & $97-104$ & $105-112$ & $113-120$ & $121-128$ & $129-136$ & $137-144$ & $145-152$ \\
\hline 0 & 2 & 0 & 1 & 0 & 3 & 0 & 0 & $153-160$ \\
5 & 3 & 1 & 1 & 0 & 4 & 2 & 1 & 2
\end{tabular}



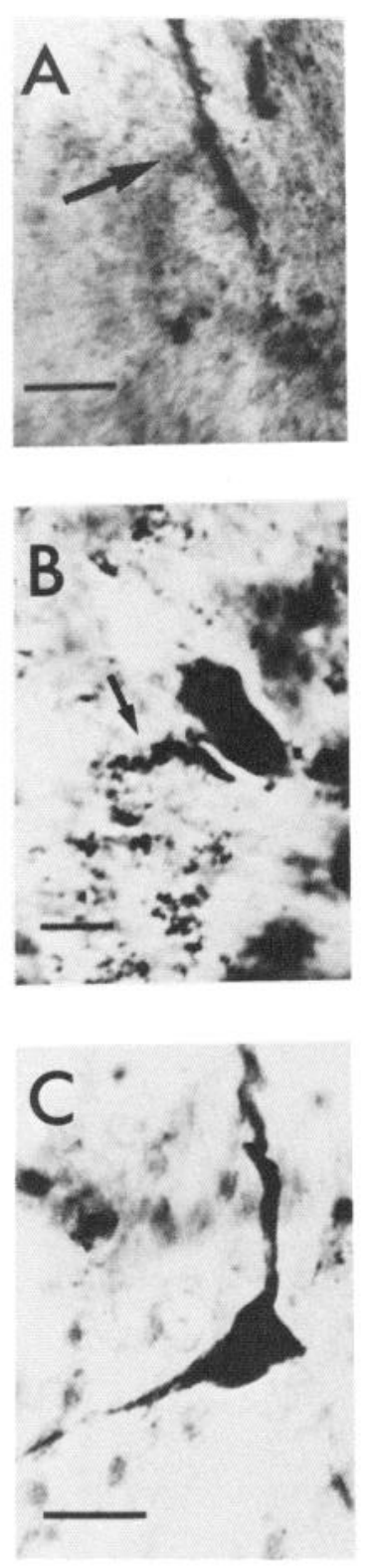

Figure 8. Example of locations marked by PHA-L. $A$, Electrode tract (arrow; magnified) from location $a$ in $D$. $B$, Process (arrow) found at location $b$ in $D$. $C$, Cell found at a comparable location in another animal (this from IC injection of PHA-L and HRP). D, Parasagittal section showing region in and bordering dorsal thalamic peduncle from which recordings were obtained. $C d$, caudate, $L D$, lateralis dorsalis (and rostral border of anterior ventralis) nucleus. Scale bars: $50 \mu \mathrm{m}, A ; 10 \mu \mathrm{m}, B ; 25$ $\mu \mathrm{m}, C ; 100 \mu \mathrm{m}, D$.

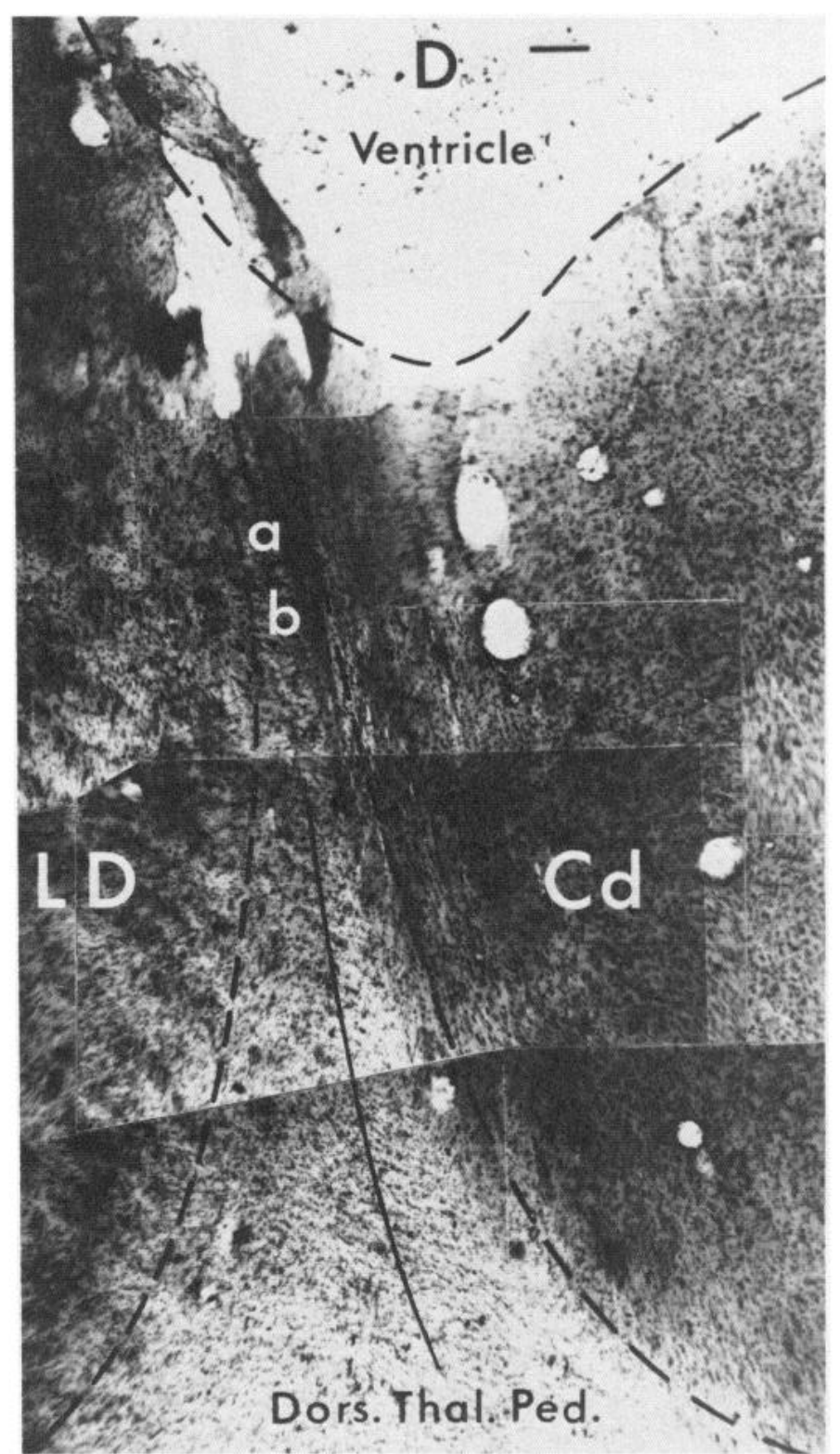

electrode penetration could have caused this, but because patterns of discharge to the CS and DS gave no evidence of significant cell injury, we attribute the lower input resistance, in vivo, to increased numbers of active synaptic conductances in the conscious, intact animals. Thus, thalamic cells in conscious animals may operate mainly in the depolarized relay mode as opposed to the hyperpolarized oscillatory mode.

Because deinactivation of low-threshold calcium requires hyperpolarization of $-65 \mathrm{mV}$ (Steriade and Llinas, 1988), LTSs may have been masked in some cells with RPs depolarized relative to that of cells in vitro. This, however, would not have accounted for the very low percentage (3\%) of LTSs found in an equally low percentage of LTSs was found in our samplings after conditioning and the lack of increased excitability to in-
This table shows excitability to a depolarizing current by auditory responsiveness of cells to CS or DS. Abbreviations are as in Table 1. our study because half of the intracellularly recorded units reached $-65 \mathrm{mV}$ during injection of $1 \mathrm{nA}$ hyperpolarizing current, and of cells with RPs $\geq 55 \mathrm{mV}$ and action potentials $\geq 60 \mathrm{mV}$.

The absence of significant changes in RP and input resistance

tracellularly applied depolarizing current in cells responsive to

\begin{tabular}{lc}
\multicolumn{2}{l}{ CS-unresponsive } \\
\hline $\mathrm{H}$ & 0 \\
\hline 0.6 & 0.6 \\
3 & 12 \\
1.4 & 0.8 \\
4 & 26 \\
\hline
\end{tabular}


the CS suggested that presynaptic mechanisms might mediate the increase in the numbers of CS-responsive cells and their activity in response to the CS after conditioning. Some contribution of changes in receptors or CS-driven synaptic conductances also cannot be ruled out. The present studies did not address the question of whether associative conditioning was responsible for the changes. [Further, nonassociative controls would be needed to answer that question (Woody, 1986).] The lower excitability to injected current after conditioning in cells unresponsive to the CS (including the DS-responsive cells) represented a postsynaptically measured effect that could have contributed to the relatively reduced activity in response to DS versus CS found in the conditioned animals.

\section{Where is the region pathway supporting audition within the rostral thalamus?}

Electrode track markings and cell recoveries (Figs. 7, 8) suggested that the auditory-responsive units were not confined to a single nucleus within the rostral thalamus. Instead, auditoryresponsive cells were found over broad regions of the rostral thalamus, ranging from the nucleus reticularis, laterally, to the anterior borders of the lateralis dorsalis and anterior ventralis nuclei, medially. Identification of the location of auditory units within the region bordering the lateralis dorsalis, ventralis anterior, anterior ventralis, and reticularis nuclei, instead of within one of these nuclei, was also advanced by our electrophysiological recordings. Reticularis neurons are known to have high rates of background activity (40-80 spikes/sec; cf. Schlag and Waszak, 1971; Frigyesi, 1972; Mulle et al., 1986). We found few cells with high spontaneous activity, and the mean rate of discharge was low (20 spikes/sec). Cells of the nearby anterior ventralis nucleus have slow firing, but show LTSs after hyperpolarizing the membrane by $5-12 \mathrm{mV}$ (Mulle et al., 1985; Pare et al., 1987). Only $3 \%$ of our cells had LTS discharges. Additional recordings over the full extent of the lateralis dorsalis nucleus had longer latencies and different patterns of auditory response than did those here (Melamed and Woody, 1989). Thus, the electrophysiological evidence did not favor localization of the auditory-responsive units in the present study to any one of these nuclei. The possibility that some activity in response to auditory stimuli was recorded from axons en passage cannot be ruled out, but when hyperpolarizing current was applied during IC recordings, most action potentials shut off rather than grew in size. [Also, in our earlier studies of HRP-marked cortical layer $\mathrm{V}$ pyramidal cells, axonal penetrations were rare even though dendrites as well as somata were penetrated (Sakai and Woody, 1980; Woody et al., 1984).]

\section{Relation to other known auditory pathways}

The ascending auditory pathways have been broadly characterized into 3 systems labeled (1) lemniscal line (also cochleotopic), (2) lemniscal adjunct (also noncochleotopic), and (3) nonspecific (Graybiel, 1972; Irvine and Phillips, 1982). Neurons of the lemniscal adjunct and nonspecific (mixed) systems are more likely to show associative changes in patterns of firing than neurons of the lemniscal line system (Olds et al., 1972; Disterhoft et al., 1982; Weinberger, 1982; Tischler and Davis, 1983).

The higher levels of the lemniscal line auditory system consist of the central nucleus of the inferior colliculus, the ventral division of the medial geniculate, and the primary auditory cortex (Graybiel, 1973). Neurons of this system are exclusively re- sponsive to auditory signals and are frequency specific and tonotopically organized (Irvine and Phillips, 1982).

The lemniscal adjunct system consists of the external and pericentral nucleus of the inferior colliculus, the thalamic posterior nuclear group, including the medial division of the medial geniculate and areas surrounding primary auditory cortex (Morest, 1965; Graybiel, 1972; Irvine and Phillips, 1982; Imig and Morel, 1983). Neurons of this system are broadly tuned and often bimodal or trimodal in response (Irvine and Phillips, 1982).

Neurons of the nonspecific (i.e., mixed) system are also characterized as being broadly tuned, with a high percentage of cells responding to stimuli of more than 1 modality (Irvine and Phillips, 1982; Sotnichenko and Istomina, 1985). At the thalamic level, these neurons are found in the midline and intralaminar nuclei, which are located just posteriorly to the rostral thalamic region. The intralaminar thalamic nuclei have projections to the neocortex (Jones and Leavitt, 1974; Macchi et al., 1977).

While further experiments will be needed to determine if the auditory-responsive cells of the rostral thalamus actually project to the motor cortex and whether they represent a continuation of the mixed or the lemniscal adjunct system, the evidence provided by these initial studies demonstrates their existence in the cat and their ability to discriminate between different auditory signals at short latencies. Separate recordings made from the centrolateral nucleus (Melamed and Woody, 1989), and full extent of the lateralis dorsalis nucleus, did not show auditory responses of sufficiently short latency to support a primary auditory projection pathway to the motor cortex. Instead, the present results suggested that such neurons were distributed in the area bordering the dorsal thalamic peduncle, among or between presently recognized nuclei within the rostral thalamic region.

\section{References}

Albe-Fessard D, Rougeul A (1958) Activities d'origine somesthesique evoquees sur le cortex non-specifique du chat anestheie au chloralose: role du centre median du thalamus. Electroencephalogr Clin Neurophysiol 10:131-152.

Disterhoft JF, Shipley MT, Kraus N (1982) Analyzing the rabbit NM conditioned nictitating membrane response. In: Conditioning: representation of involved neural functions (Woody CD, ed), pp 433449. New York: Plenum.

Engel J Jr, Woody CD (1972) Effects of character and significance of stimulus on unit activity at coronal-pericruciate cortex of cat during performance of conditioned motor response. J Neurophysiol 35:220229.

Evans EF, Whitfield IC (1966) Classification of unit responses in the auditory cortex of the unanesthetized, unrestrained cat. J Physiol (Lond) 181:476-493.

Frigyesi TL (1972) Intracellular recordings from neurons in dorsolateral thalamic reticular nucleus during capsular, basal ganglia and midline thalamic stimulation. Brain Res 48:157-172.

Gabriel M, Foster K, Orona E, Saltwick SE, Stanton M (1980) Neuronal activity of cingulate cortex, anteroventral thalamus and hippocampal formation in discriminative conditioning: encoding and extraction of the significance of conditional stimuli. In: Progress in psychobiology and physiological psychology, Vol 9 (Sprague JM, Epstein AN, eds), pp 125-232. New York: Academic.

Gabriel M, Orona E, Foster K, Lambert RW (1982) Mechanism and generality of stimulus significance coding in mammalian model system. In: Conditioning: representation of involved neural functions (Woody CD, ed), pp 535-566. New York: Plenum.

Gerfen CR, Sawchenko PE (1984) An anterograde neuroanatomical tracing method that shows the detailed morphology of neurons, their axons and terminals: immunohistochemical localization of an axonally transported plant lectin, Phaseolus vulgaris leucoagglutinin (PHA-L). Brain Res 290:219-238.

Goldstein MH Jr, Abeles M, Daly RL, McIntosh J (1960) Functional 
architecture in cat primary auditory cortex: tonotopic organization. J Neurophysiol 33:188-197.

Graybiel AM (1972) Some fiber pathways related to the posterior thalamic region in the cat. Brain Behav Evol 6:363-932.

Graybiel AM (1973) The thalamo-cortical projection of the so-called posterior nuclear group: a study with anterograde degeneration methods in the cat. Brain Res 49:229-244.

Hirano T, Woody C, Birt D, Aou S, Miyake J, Nenov V (1987) Pavlovian conditioning of discriminatively elicited eyeblink responses with short onset latency attributable to lengthened interstimulus intervals. Brain Res 400:171-175.

Imig TJ, Morel A (1983) Organization of the thalamocortical auditory system in the cat. Annu Rev Neurosci 6:95-120.

Irvine DRF, Phillips DP (1982) Polysensory "association" areas of the cerebral cortex. In: Cortical sensory organization, Vol 3, Multiple auditory areas (Woolsey CN, ed), pp 111-156. Clifton, NJ: Humana.

Jahnsen H, Llinas R (1984) Electrophysiological properties of guineapig thalamic neurones: an in vitro study. J Physiol (Lond) 349:205226.

Jones EG, Leavitt RY (1974) Retrograde axonal transport and the demonstration of non-specific projections to the cerebral cortex and striatum from thalamic intralaminar nuclei in the rat, cat and monkey. J Comp Neurol 154:349-378.

Kim EH-J, Woody CD, Berthier NE (1983) Rapid acquisition of conditioned eye blink responses in cats following pairing of an auditory CS with glabella tap US and hypothalamic stimulation. J Neurophysiol 49:767-779.

Kita H, Kitai ST (1986) Electrophysiology of rat thalamocortical relay neurons: an in vivo intracellular recording and labeling study. Brain Res 371:80-89.

LeDoux JE, Farb C, Ruggiero DA (1990) Topographic organization of neurons in the acoustic thalamus that project to the amygdala. $J$ Neurosci 10:1043-1054.

Macchi G, Bentivoglio M, D'atena C, Rossini P, Tempesta E (1977) The cortical projections of the thalamic intralaminar nuclei restudied by means of the HRP retrograde axonal transport. Neurosci Lett 4 : 121-126.

Melamed O, Woody CD (1989) Responses of cells of laterodorsal and lateral posterior thalamus to auditory stimuli before and after conditioning of a Pavlovian eyeblink reflex. Soc Neurosci Abstr 15:889.

Morest DK (1965) The lateral tegmental system of the midbrain and the medial geniculate body: study with Golgi and Nauta methods in cat. J Anat 99:611-634.

Mulle C, Steriade M, Deschenes M (1985) Absence of spindle oscillations in the cat anterior thalamic nuclei. Brain Res 334:169-171.

Mulle C, Madariaga A, Deschenes M (1986) Morphology and electrophysiological properties of reticularis thalami neurons in cat: in vivo study of a thalamic pacemaker. J Neurophysiol 6:2134-2145.

Neff WD (1961) Neural mechanisms of auditory discrimination. In: Sensory communication (Rosenblith WA, ed), pp 259-278. Cambridge, MA: MIT Press.

Olds J, Disterhoft JF, Segal M, Kornblith CL, Hirsh R (1972) Learning centers of rat brain mapped by measuring latencies of conditioned unit responses. J Neurophysiol 35:202-219.

Pare D, Steriade M, Deschenes M, Oakson G (1987) Physiological properties of anterior thalamic nuclei, a group devoid of inputs from the reticular thalamic nucleus. J Neurophysiol 57:1669-1685.

Porter L, Sakamoto K (1988) The organization and synaptic relationship of the projection from the primary sensory to the primary motor cortex in the cat. J Comp Neurol 271:387-396.

Purpura DP, Shofer RJ (1963) Intracellular recording from thalamic neurons during reticulocortical activation. J Neurophysiol 26:494505 .
Purves RD (1981) Microelectrode methods for intracellular recording and iontophoresis. London: Academic.

Roy JP, Clercq M, Steriade M, Deschenes M (1984) Electrophysiology of neurons of lateral thalamic nuclei in cat: mechanisms of long-lasting hyperpolarizations. J Neurophysiol 51:1220-1235.

Sakai H, Woody CD (1980) Identification of auditory responsive cells in coronal-pericruciate cortex of awake cats. J Neurophysiol 44:223231

Sakai M, Sakai H, Woody C (1978) Intracellular staining of cortical neurons by pressure microinjection of horseradish peroxidase and recovery by core biopsy. Exp Neurol 58:138-144.

Schlag J, Waszak W (1971) Electrophysiological properties of units in the thalamic reticular complex. Exp Neurol 32:79-97.

Snider RS, Niemer WT (1961) Stereotaxic atlas of the cat brain. Chicago: University of Chicago.

Sotnichenko TS, Istomina LA (1985) Ascending and descending efferent pathways of the reticular formation of the cat mesencephalon (an autoradiographic investigation). Arkh Anat Gistol Embriol 89: 22-31.

Steriade M (1987) Thalamus. In: Encyclopedia of neuroscience, Vol II (Adelman G, ed), pp 1204-1208. Boston: Birkhauser.

Steriade M, Glenn LL (1982) Neocortical and caudate projections of intralaminar thalamic neurons and their synaptic excitation from midbrain reticular core. J Neurophysiol 48:352-371.

Steriade M, Llinas RR (1988) The functional states of the thalamus and the associated neuronal interplay. Physiol Rev 68:649-742.

Thompson RF, Sindberg RH (1960) Auditory response fields in association and motor cortex of cat. J Neurophysiol 23:87-105.

Thompson RF, Johnson RH, Hoopes JJ (1963) Organization of auditory, somatic sensory and visual projections to association fields of cerebral cortex in the cat. J Neurophysiol 26:343-364.

Tischler MD, Davis M (1983) A visual pathway that mediates fear conditioned enhancement of acoustic startle. Brain Res 276:55-71.

Weinberger NM (1982) Sensory plasticity and learning: the magnocellular medial geniculate nucleus of the auditory system. In: Conditioning: representation of involved neural functions (Woody $C D$, ed), pp 697-710. New York: Plenum.

Winer BJ (1971) Statistical principles in experimental design, 2d ed. New York: MacGraw.

Woody CD (1986) Understanding the cellular basis of memory and learning. Annu Rev Psychol 37:433-493.

Woody CD, Black-Cleworth P (1973) Differences in excitability of cortical neurons as a function of motor projection in conditioned cats. J Neurophysiol 36:1104-1116.

Woody CD, Brozek G (1969) Changes in evoked responses from facial nucleus of cat with conditioning and extinction of an eye blink. $J$ Neurophysiol 32:717-726.

Woody CD, Yarowsky PJ (1972) Conditioned eye blink using electrical stimulation of coronal-precruciate cortex as conditional stimulus. J Neurophysiol 35:242-252.

Woody CD, Vassilevsky NN, Engel J Jr (1970) Conditioned eye blink: unit activity at coronal-precruciate cortex of the cat. J Neurophysiol 33:851-864.

Woody C, Yarowsky P, Owens J, Black-Cleworth P, Crow T (1974) Effect of lesions of cortical motor areas on acquisition of conditioned eyeblink in the cat. J Neurophysiol 37:385-394.

Woody CD, Knispel JD, Crow TJ, Black-Cleworth PA (1976) Activity and excitability to electrical current of cortical auditory receptive neurons of awake cats as affected by stimulus association. J Neurophysiol 39:1045-1061.

Woody CD, Gruen E, McCarley K (1984) Intradendritic recording from neurons of motor cortex of cats. J Neurophysiol 51:925-938. 